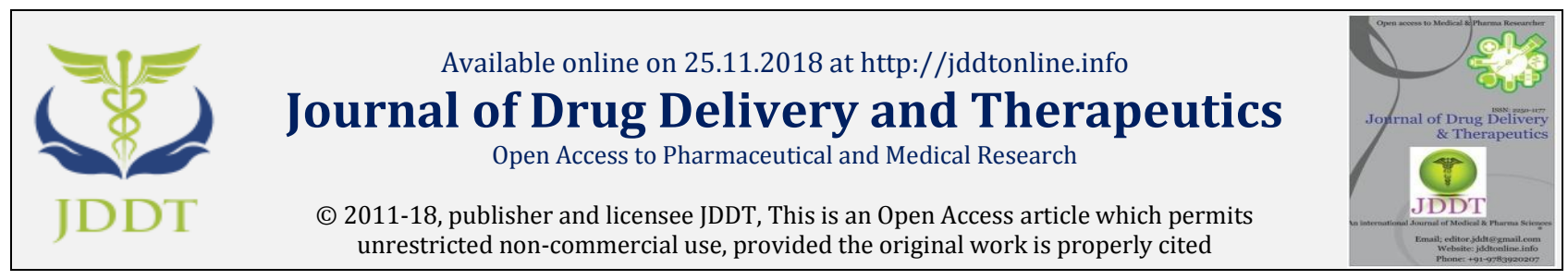

Open $\odot$ Access

Review Article

\title{
A comprehensive review on Liposomes: a novel drug delivery system
}

\author{
Harshita Mishra, Vaishali Chauhan, Kapil Kumar*, Deepak Teotia \\ Global Institute of Pharmaceutical Education and Research, Kashipur, Uttrakhand, India
}

\begin{abstract}
Liposome was derived from two Greek words "Lipos meaning fat and Soma meaning body". Liposome were spherical shaped vesicles consist of phospholipids and cholesterol. Due to their size hydrophobic and lipophilic character they are very promising system for drug delivery. This novel drug delivery system aims to target the drug directly to the site of action. Liposomes are very biocompatible and stable and have unique property to entrap both hydrophilic drug and lipophilic drug (amphiphatic nature) to its compartment and lead to controlled release effect. They are of 0.05- 5.0 micrometer in diameter. Liposomes are used for the treatment of various diseases like tumors or cancer. This article provides an overview of Liposomal Drug Delivery System and various aspects related to liposome that can be studied.
\end{abstract}

Keywords: Liposomes, novel delivery, amphiphatic, controlled release.

Article Info: Received 08 Oct, 2018; Review Completed 20 Nov 2018; Accepted 25 Nov 2018; Available online 25 Nov 2018

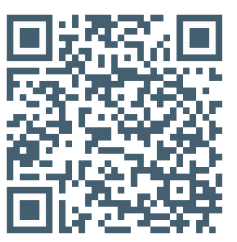

Cite this article as:

Mishra H, Chauhan V, Kumar K, Teotia D, A comprehensive review on Liposomes: a novel drug delivery system, Journal of Drug Delivery and Therapeutics. 2018; 8(6):400-404 DOI: http://dx.doi.org/10.22270/jddt.v8i6.2071

*Address for Correspondence:

Kapil Kumar, Global Institute of Pharmaceutical Education and Research, Kashipur, Uttrakhand, India

\section{INTRODUCTION}

Liposomes were spherical shaped concentric vesicles derived from two Greek words lipos means fat and soma means body ${ }^{1}$. Liposome were first made by Bangham et al in 1961, it was an accidental discovery in which he scattered the phosphatidyl choline molecule in water, during this he found that the molecule was forming a closed bilayer structure having an aqueous phase which were entrapped by a lipid bilayer ${ }^{2}$. Liposome very useful because act as a carrier for a variety of drugs, having a potential therapeutic action or other properties. Liposome is colloidal carriers, having a size range of $0.01-5.0 \mu \mathrm{m}$ in diameter. Drug encapsulated by liposome achieve therapeutic level for long duration as drug must first be release from liposome before metabolism and excretion ${ }^{3}$. They are small artificial vesicles of spherical shape that can be created from cholesterol and natural non-toxic phospholipids. Due to their size and hydrophobic and hydrophilic character (besides biocompatibility), liposome's are promising systems for drug delivery ${ }^{4}$. There is a unique ability of liposomes to entrap drugs of both aqueous and the lipid phase and it makes them attractive drug delivery systems for hydrophilic and hydrophobic drugs 5 .

Liposomes are the novel drug delivery system that aims to deliver the drug directly to the place of action. They have potential to accommodate both hydrophilic and lipophilic compounds to protect the drug from degradation and release the active ingredients in a controlled manner6. It has been found that glycerol is the backbone of a molecule that's why phospholipid containing glycerol were found to be an essential component of liposomal formulation and it represents 505 of lipid weight?

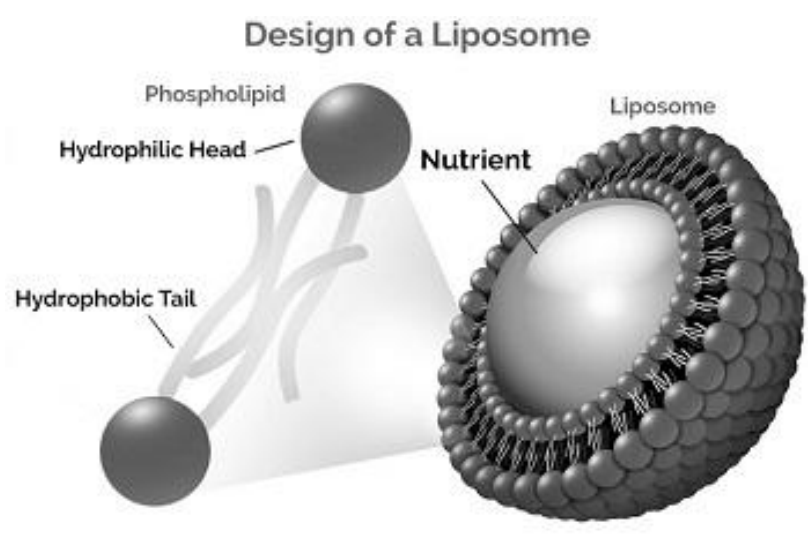

Figure 1: Design of liposome

The structural components are:

\section{1) Phospholipids}

Phospholipids are the major structural components of liposome. The most common phospholipids used in liposomal preparation are Phosphatidylcholine $\left(\mathrm{PC}^{8}\right)$. 
Phosphatidyl-choline is an amphiphatic molecule consist of-

- A hydrophilic polar head group, phosphocholine

- A glycerol bridge

- A pair of hydrophobic acyl hydrocarbon chains

The chemical structure of naturally occurring Phosphatidylcholine has a glycerol moiety attached to two acyl chains which may be saturated or unsaturated. The stability of liposome membrane depends on the packing of hydrocarbon chains of the lipid molecules ${ }^{9}$. The nature of the fatty acid in lipid molecule, such as number of double bonds in the chain, is responsible for bilayer properties such as elasticity and phase behavior ${ }^{10}$. Phospholipids are very abundant in nature and which contains choline is used for the preparation of liposomes.

Examples of phospholipids are-

- Phosphatidyl choline (Lecithin) PC

- Phosphatidyl ethanolamine(Cephalin)-PE

- $\quad$ Phosphatidyl serine (PS)

- $\quad$ Phosphatidyl Glycerol (PG)

\section{2) Cholestrol}

Cholesterol is another important structural component of liposome. It is a commonly used sterol. The addition of sterols modulates the function of stability and rigidity. It does not by itself form a bilayer structure ${ }^{11}$. It gets incorporated into phospholipids in a very high concentration up to 1:1 or 2:1 molar ratio of cholesterol to phosphatidyl choline. The presence of cholesterol in the lipid bilayer enhances the stability and form highly ordered and rigid membrane structure ${ }^{12}$.

Cholesterol reduces the permeability of water soluble molecules and improves the fluidity and stability of biological membrane. The interaction and destabilization of liposomes was prevented by cholesterol ${ }^{13}$.

\section{ADVANTAGES OF LIPOSOMES}

- Amphiphatic in nature so entrap both kind of drugs either water soluble or insoluble

- Increased efficacy and therapeutic index of drug 14 .

- $\quad$ Non ionic
- Liposome helps to reduce exposure of sensitive tissues to toxic drugs.

- Provides selective passive targeting to tumor tissues.

- Prevent oxidation of drugs.

- Liposomes are biodegradable ${ }^{15}$

- Biocompatible

- Liposome increases stability of drug ${ }^{16}$

- Site avoidance effect.

- Improve protein stabilization ${ }^{17}$.

- Provide sustained release.

- Direct interaction of drug with cell.

- $\quad$ Site avoidance effect.

\section{DISADVANTAGES OF LIPOSOMES}

- Low solubility.

- Short half life.

- $\quad$ Production cost is high ${ }^{18}$.

- Leakage and fusion of encapsulated drug may occur.

- Oxidation of phospholipids may occur ${ }^{19}$.

- Less stable.

\section{MECHANISM OF ACTION OF LIPOSOMES}

Liposome performs their action by four different mechanism .They are as follows:

1. Endoytosis - This take place by phagocytic cells of reticuloendothelial system such as neutrophills ${ }^{20}$.

2. Adsorption - It occurs to the cell surface by non specific electrostatic forces or by interaction with cell surface components ${ }^{21}$.

3. Fusion- It occurs by the insertion of liposomal bilayer into plasma membrane with continuous release of liposomal content into the cytoplasm ${ }^{22}$.

4. Lipid exchange- In this transfer of liposomal lipids to the cellular membrane without association of liposomal contents ${ }^{23}$.

\section{CLASSIFICATION OF LIPOSOMES}

There are various classification of liposome based on-

a) Structural features

Table 1: Liposomes based on vesicle type ${ }^{24}$

\begin{tabular}{|l|l|l|}
\hline Vesicle type & Diameter Size & No. of Lipid Layer \\
\hline Multi lamellar large vesicles (MLV) & More than $0.5 \mu \mathrm{m}$ & $5-25$ \\
\hline Oligo lamellar vesicles (OLV) & $0.1-1.0 \mu \mathrm{m}$ & Approx 0.5 \\
\hline Uni lamellar vesicles (UV) & All size ranges & 1 \\
\hline Small Uni lamellar vesicles (SUV) & $20-100 \mathrm{~nm}$ & 1 \\
\hline Medium sized uni lamellar vesicles (MUV) & More than 100nm & 1 \\
\hline Large Uni lamellar vesicles (LUV) & More than $100 \mathrm{~nm}$ & 1 \\
\hline Giant Uni lamellar vesicles (GUV) & More than $1.0 \mu \mathrm{m}$ & 1 \\
\hline Multi Vesicular vesicles (MVV) & More than $1.0 \mu \mathrm{m}$ & Multicompartmental structure \\
\hline
\end{tabular}

b) Based upon Conventional Liposomes 25

$>$ Natural lecithin mixtures

$>$ Liposome with glycolipids

$>$ Synthetic identical chain phospholipids

c) Based on method of preparation of liposomes 26
Table 2: Liposomes based on vesicle type

\begin{tabular}{|l|l|}
\hline $\begin{array}{l}\text { Vesicle } \\
\text { Type }\end{array}$ & Method of preparation \\
\hline REV & Prepared by Reverse phase evaporation method \\
\hline MLV & By Reverse phase evaporation method \\
\hline VET & Prepared by extrusion method \\
\hline FUV & Vesicles prepared by fusion \\
\hline FPV & Vesicles prepared by French press \\
\hline
\end{tabular}


d) Based upon Specialty liposomes

$>$ Lipoprotein coated

$>$ Carbohydrate coated

$>$ Bipolar fatty acid

$>$ Antibody directed

\section{METHODS OF PREPARATION OF LIPOSOMES}

There are different methods involved in the preparation of liposomes

- General method of preparation - It involves four steps for the preparation of liposmes ${ }^{27}$.

Drying down lipids from organic solvents

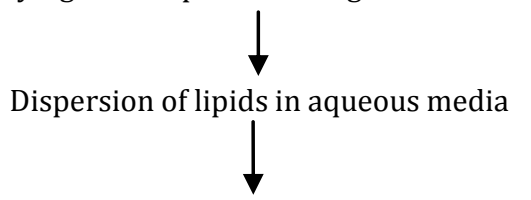

Purification of resultant liposomes

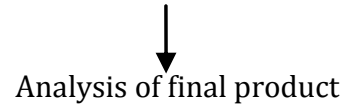

\section{I) Passive Loading Techniques}

A) Mechanical dispersion methods

Lipid hydration method: This is the most common method of preparing MLV.

In this method lipid solution was dried so that a thin film was formed at the bottom of RBF and then film was hydrated by adding aqueous buffer and vortexing the mixture. The hydration step is done at a temperature above the gel liquid crystalline transition temperature. The compound to be encapsulated are added either to aqueous buffer or organic solvent depending upon their solubility ${ }^{28}$.
Micro emulsification: This method is used for preparing SLV. It can be achieved by microemulsifying lipid compositions using high shearing stress generated from high pressure homogenizer.

Dried reconstituted vesicles: In this method liposomes are added to an aqueous solution containing drug or mixed with lyophilized protein, followed by dehydration of mixture.

Freeze thaw method- In this method SUVs were frozen rapidly by slow thawing techniqur. The formation of unilamellar occurs due to this reason.

\section{B) Solvent Dispersion -}

Ethanol injection: A lipid solution of ethanol was added to an aqueous buffer which immediately forms MLV.

Ether infusion: A solution of lipids dissolved in diethylether and is slowly injected to a solution of the material to be encapsulated at temperature $55-60 \circ \mathrm{C}^{29}$.

C) Detergent: Lipids were solubilized by detergents at their critical miscelles concentration. As detergent is removed, miscelles become richer in phospholipids and finally combine to form LUVs.

\section{II) Active Loading Techniques}

Proliposomes: In this method lipid and drug were coated onto a soluble carrier to form free flowing granular material in pro-liposome which forms an isotonic liposomal suspension on hydration ${ }^{30}$.

Lyophillization: The removal of water from products in a frozen state at a reduced pressure is called Lyophillization. This method is generally used to dry the products that are thermolabile

\section{MARKETED FORMULATIONS OF LIPOSOMES}

In 1995, Doxil (PEGylated liposome-encapsulate doxorubicin) became the first liposome drug delivery system approved for human use by the US FDA. There was list of marketed formulations of liposomes.

Table 3: Market product of liposomes

\begin{tabular}{|l|c|c|l|}
\hline S.NO & PRODUCT NAME & DRUG & COMPANY \\
\hline 1. & Ambisome & Amphotericin B & NeXstar pharmaceuticals Inc.CO \\
\hline 2. & Abelcet & Amphotericin B & The Liposome company N.J. \\
\hline 3. & Amphocil & Amphotericin B & Sequus pharmaceuticals Inc.CA \\
\hline 4. & Doxil & Doxorubicin & Sequus pharmaceuticals Inc.CA \\
\hline 5. & DaunoXome & Daunorubicin & NeXstar pharmaceuticals Inc.CO \\
\hline 6. & Mikasome & Amikacin & NeXstar pharmaceuticals Inc.CO \\
\hline 7. & DC99 & Doxorubicin & Liposome CO.,NJ,USA \\
\hline 8 & Epaxel & Hepatitis A vaccine & Swiss Serum Institue,Switzerland \\
\hline 9. & ELA max & Lidocaine & Biozone Labs,CA,USA \\
\hline
\end{tabular}

\section{EVALUATIONS OF LIPOSOMES}

1) Vesicle shape and lamellarity: The shape of the vesicles were studied by using electron microscope.

2) Particle size and distribution: The size analysed by an analyzer based on laser diffraction theory focused with minimum power of $5 \mathrm{MW}^{31}$.

3) Entrapment Efficiency - It determines amount and rate of entrapment of water soluble agents in aqueous compartment of liposomes.
This can be calculated by a given formula

$$
\% \text { Entrapment Efficiency }=\frac{\text { Entrapped Drug } \times 100}{\text { Total Drug }}
$$

4) Trapped Volume - It is an important parameter related to liposomes .It is aqueous entrapped volume per quantity of lipids. This can vary from 0.5 to 30 microlitre/micromol ${ }^{32}$

5) In vitro drug release - This can be carried by using Franz Diffusion cell which has a diameter of $25 \mathrm{~mm}$.It 
contains reservoir compartment of $22 \mathrm{ml}$ which was filled with buffer which contains $20 \% \mathrm{v} / \mathrm{v}$ methanol to maintain sink condition.

6) Percentage yield of liposomes- The prepared liposomes were prepared and collected. The measured weight was divided by the total amount of drug and ingredients which were used for the preparation of liposomes ${ }^{33}$.

\section{STABILITY OF LIPOSOMES}

Therapeutic efficacy of drug molecule is governed by stability of liposomes. There are two types of stability-

Physical Stability- There are various physical processes which effects the shelf life of liposomes like fusion, aggregation and shape and size .The general problem that occurs is leakage of drug material. The morphology and size distribution are important parameters for accessing stability.Physical stability can be maintained by avoiding excess unsaturation in the phospholipids. They must be stored at $4{ }^{\circ} \mathrm{C}$ with no freezing and light exposure ${ }^{34}$.

Chemical Stability- Phospholipids are unsaturated fatty acids prone to hydrolysis alter the stability of drug product. Liposomes can be prevented from oxidative degradation by adding antioxidants such as butylated hydoxy anisole ${ }^{35}$.

\section{APPLICATIONS OF LIPOSOMES}

$>$ Respiratory Diorders- The liposomes have been found to possess beneficial effects in the treatment of several respiratory disorders, reason being their better sustained release, improved stability and reduced toxicity than ordinary aerosols. Liquid or dry form can be taken for inhalation of liposome and release of drug has been reported to occur during nebulization .

$>$ Ophthlamic Disorders- Dry eyes, keratitis, corneal transplant rejection, uveitis, ondopthelmitis and proliferative vitro retinopathy are the examples of eye disorders against which liposomes have been found to possess beneficial effects. The drug verteprofin that is

\section{REFERENCES}

1. Joshi A J, R P Patel Liposomes: Emerging Trends in Novel Drug Delivery with Present and Future Challenges International Journal of Pharmaceutical and Biological Archives 2015; 6(2):3 - 8

2. Bangham AD and RW Horne. "J Mol Biol”, 1964; 8: 660-668.

3. Lasic, D.D. Novel application of liposomes. Tibitech. 1998; 16:307-321

4. Mayer, L.D., Hope, M.J., Cullis, P.R., Janoff, A.S. Solute distributions and trapping efficiencies observed in freezethawed multilmellar vesicles. Biochim. Biophys. Acta 1985; 817:193-196.

5. Vyas, S.P., Khar, R.K. 2006. Targeted And Controlled Drug Delivery: Novel Carrier Systems. Edition 1, CBS Publishers and Distributor, New Delhi.pp.421-427.

6. Maurya SD, Prajapati S, Gupta A, Saxena G, Dhakar RC, Formulation development and evaluation of ethosome of stavudine, Int J Pharm Edu Res. 2010; 13(16).

7. Chen X, Huang W, Wong BC, Yin L, Wong YF, Xu M, ET al. Liposomes prolong the therapeutic effect of anti-asthmatic medication via pulmonary delivery. Int J Nanomed, 2012; 7:1139-1148.

8. Fujisawa T, Miyai H, Hironaka K, Tsukamoto T, Tahara K, Tozuka Y, et al. Liposomal diclofenac eye drop formulations targeting the retina: formulation stability improvement using surface modification of liposomes. Int J Pharm, 2012; 436: 564-567. found to be effective against eye disorders has been recently approved as liposomal formulation ${ }^{35}$.

$>$ Tumor therapy- Carrier of small cytotoxic molecule and vehicles used for macromolecule such as cytokines.

$>$ Immunological adjuvants in vaccines - Liposomes used in immunoadjuvant, immunodiagnosis .

$>$ Liposomes as protein drug delivery- They are used to enhanced drug solubilization

$>$ Pulmonary Application - They are useful tools for pulmonary delivery of drugs due to their solubilization capacity ${ }^{12}$.

$>$ Liposomes in Cosmetics- They are used in cosmetics because their physiology is similar to the cell membrane and they release materials to the cells ${ }^{16}$.

$>$ Site specific targeting- The immunoliposomes are able to recognize and binds to target cells with greater specificity.

$>$ Gene therapy- Liposomes are used widely in gene applications to cure diseases.

\section{ADVANCEMENTS IN LIPOSOMES}

$>$ Ethosomes- They are efficient at delivering to the skin composed of soya phosphatidylcholine and $30 \%$ ethanol ${ }^{36}$.

$>$ Immuno liposomes- They were modified with antibodies.

$>$ Niosomes- They is small unilamellar vesicles made from non ionic surfactants?

$>$ Stealth liposomes- They are new type of liposomes which were prepared to improve stability and lengthen their half life in circulation. Coating of liposomes should be done by poly ethylene glycol (PEG) for preparing these liposomes ${ }^{8}$.
9. Vishvakrama, P., \& Sharma, S. Liposomes: an overview. Journal of Drug Delivery and Therapeutics, 2014; 47-55. https://doi.org/10.22270/jddt.v0i0.843

10. Samadikhah HR, Majidi A, Nikkhah M, Hosseinkhani S. Preparation, characterization, and efficient transfection of cationic liposomes and nanomagnetic cationic liposomes. Int J Nanomedicine, 2011; 6: 2275-2283.

11. Paecharoenchai O, Niyomtham N, Apirakaramwong A, Ngawhirunpat T, Rojanarata T, Yingyongnarongkul BE, et al Structure Relationship of Cationic Lipids on Gene Transfection Mediated by Cationic Liposomes. AAPS Pharm Sci Tech, 2012; in press.

12. Li X, Chen D, Le C, Zhu C, Gan Y, Hovgaard L. Novel mucuspenetrating liposomes as a potential oral drug delivery system: preparation, in vitro characterization, and enhanced cellular uptake. Int J Nanomedicine, 2011; 6: 3151-3162.

13. Ejiogu Deborah Chioma. Formulation and evaluation of etodolac niosomes by modified ether injection technique. Universal Journal of Pharmaceutical Research. 2016; 1(1): 16.

14. Elsaied Hamada Elsaied, Hamdy Mohamed Dawaba, Elsherbini Ahmed Ibrahim, Mohsen Ibrahim Afouna Investigation of proniosomes gel as a promising carrier for transdermal delivery of Glimepiride. Universal Journal of Pharmaceutical Research. 2016; 1(2): 1-18.

15. Sipai Altaf Bhai. M*, Vandana Yadav, Mamatha. Y, Prasanth V.V Department of pharmaceutics Gautam college of 
Pharmacy,Lipoosmes an Overview,Journal of pharmaceutical and Scientific innovation,accepted on 24/01/12.

16. Kant Shashi*, Kumar Satinder, Prashar Bharat,A complete review on liposomes ,International Research Journal Of Pharmacy ISSN 2230-8407

17. Sharma Vijay $\mathrm{K}$,Liposomes present prospective and future challenges ,International journal of current pharmaceutical review and Research Vol 1,Issue 2 , Aug-Oct-2010 ISSN :0976 $822 \mathrm{X}$

18. Formulation and evaluation of liposomal drug delivery system of decitabine T. Veena* Dr. Manichandrik, Madav, Madhuri, Mounika, Bindu Rani , Ashwini Formulation and evaluation of liposomal drug delivery system of decitabine, Vol 6,Issue 3 , July -Sep 2017.

19. Nasim Karami1, Eskandar Moghimipour2,3, Anayatollah Salimi2,3 Liposomes as a Novel Drug Delivery System: Fundamental and Pharmaceutical Application.

20. Kaur D., Kumar S., Niosomes: present scenario and future aspects. Journal of Drug Delivery and Therapeutics, 2018 8(5):35-43. https://doi.org/10.22270/jddt.v8i5.1886

21. Hong MS et al., Prolonged blood circulation of methotrexate by modulation of liposomal composition, Drug Delivery 2001; 8:231-237

22. Jesorka A, al., Liposomes: technologies and analytical applications, Annu. Rev. Anal. Chem. 1 (2008) 801-832

23. Vemuri S, et al., Preparation and characterization of liposomes as therapeutic delivery systems: a review, Pharm. Acta Helv. 1995; 70:95-111

24. James ND, et al., Liposomes doxorubicin (Doxil): an effective new treatment for Kaposi's sarcoma in AIDS, Clin. Oncol.(R. Coll. Radiol.) 1994; 6(5):294-296

25. Laouini A et al., Preparation, characterization and applications of liposomes: state of the art, J. Colloid Sci. Biotechnol. 2012; 1:147-168.
26. Gregoriadis G, et al., Stability of liposomes in vivo and in vitro is promoted by their cholesterol content and the presence of blood cells, Biochem. Biophys. Res. Commun. 1979; 89:1287-1293.

27. Shailesh S, Neelam S, Sandeep K, Gupta GD, Liposomes: A review, Journal of Pharmacy Research 2009; 2(7):11631167.

28. Deshmukh RR, Gawale SV, Bhagwat MK, Ahire PA, Derle ND, A Review on: liposomes, World journal of pharmacy and pharmaceutical sciences, Issue 03, 506-517.

29. Godbole MD, Mathur VB, Selection of phospholipid and method of formulation for optimum entrapment and release of lamivudine from liposome. Journal of Drug Delivery and Therapeutics, 2018; 8(5-s):175-183. https://doi.org/10.22270/jddt.v8i5-s.1935

30. John DF, Yunus AA, Chigbo UJ, Paul US, Ikenna E. Tolnaftate loaded liposomes-design, and in-vitro evaluation. Universal Journal of Pharmaceutical Research. 2016; 1(2): 48-53.

31. Anwekar H, Patel S, Singhai AK, Liposomes as drug carriers International journal of Pharmacy and life sciences, July 2011.

32. Dwivedi C, Yadav R, Tiwari SP, Satapathy T, Roy A, Role of liposomes in novel drug delivery system, Journal of drug delivery and therapeutics 2014; 4(2):116-129.

33. Priyanka R Kulkarni, Jaydeep D Yadav, Kumar A Vaidya. Liposomes: A Novel Drug Delivery System. International journal of current Pharmaceutical and Research 2011; 3(2).

34. Yadav Y, Kumar S, Pandey D, Dutta RK, Liposomes for drug delivery ,Journal of Biotechnology and Biomaterials , 2017.

35. Ugochukwu AE, Nnedimkpa OJ, Rita NO. Preparation and characterization of Tolterodine tartrate proniosomes, Universal Journal of Pharmaceutical Research. 2017; 2(2):2225. 